Check for updates

\section{The BMJ}

Cite this as: BMJ 2020;369:m2433 http://dx.doi.org/10.1136/bmj.m2433 Published: 16 June 2020

\title{
Let all international health and social care workers who worked in the pandemic stay in the UK, says college
}

Abi Rimmer

The NHS must secure a new deal for international health and social care workers now that the covid-19 pandemic is subsiding, says the Royal College of Physicians (RCP).

As the initial peak of the pandemic passes and patients with non-urgent conditions can access care once again, the college has set out nine priorities for the NHS (see box). ${ }^{1}$

These include granting indefinite leave to remain for overseas health and social care workers, and their families, who have contributed during the pandemic, and expanding the proposed NHS visa ${ }^{2}$ to include social care staff.

The college is also calling for clinicians to be allowed time and space to rest and recuperate and for all NHS staff to be given time to support service redesign, planning, and implementation.

RCP registrar Donal O’Donoghue said, “Our healthcare system must not simply return to how it was pre-pandemic. As the NHS rebuilds over the next 18 months, we must seize the moment to make long overdue changes to improve services for patients.

"This will not be easy, but the challenges we face are not insurmountable. By providing clinical leadership, physicians will play a key role in successfully rebuilding the service, working in close collaboration with other healthcare professionals.”

\section{The RCP's priorities:}

- 1 Support the NHS to resume services with improved integrated ways of working

- 2 Increase the workforce

- 3 Encourage protected time for quality improvement, service redesign, and research

- 4 Support education and development, particularly for trainees

- 5 Secure a new deal for international workers

- 6 Enhance person centred care, including fair access for patients with multiple conditions

- 7 Enable involvement in, and access to, research for all

- 8 Make social care sustainable

- 9 Harness the potential of digital health

1 Rebuilding the NHS: RCP priorities for the resetting of services. www.rcplondon.ac.uk/guidelines-policy/rebuilding-nhs-rcp-priorities-resetting-services.

2 lacobucci G. UK will still attract overseas doctors despite ending free movement, government insists. BMJ 2020;368:m942 doi: 10.1136/bmj.m942 pmid: 32144174 determined by BMJ. You may use, download and print the article for any lawful, non-commercial purpose (including text and data mining) provided that all copyright notices and trade marks are retained. 